\title{
O conceito de solo sob o olhar de crianças do Ensino Fundamental em escolas de São Paulo-SP
}

\author{
The concept of soil under children eyes in the elementary schools in São Paulo-SP
}

\author{
Déborah de Oliveira*1 \\ ${ }^{1}$ Departamento de Geografia, Universidade de São Paulo, São Paulo, Brasil
}

\begin{abstract}
Resumo
O conceito de solo varia de acordo com o olhar de cada indivíduo e do uso que se faz dele. A abordagem pedológica na educação ambiental teve início na década de 90 do século XX, procurando despertar o uso racional do solo e sua conservação, tanto na educação formal como na não formal. No Brasil, os chamados Projetos Solo na Escola, tiveram início no ano de 2003, com o mesmo objetivo. Os Parâmetros Curriculares Nacionais (PCNs) trazem o tema solo como um tema transversal no Ensino Fundamental, tanto nas disciplinas de Ciências como em Geografia. Procuramos investigar o que as crianças do Ensino Fundamental conhecem sobre o solo em escolas de São Paulo. Para isso, participamos de oficinas e oferecemos palestras para crianças e professores. Percebemos que o saber da criança não difere muito do saber popular sobre o solo, mesmo já tendo aprendido sobre o tema na escola. Neste sentido, ressaltamos importância da Educação em Solos para que este não seja visto somente para fins econômicos, mas também como importante elemento do meio ambiente e da manutenção da vida.
\end{abstract}

Palavras-chave: Educação em Solos, Projeto Solo na Escola, Ensino Fundamental.

\begin{abstract}
The concept of soil varies with the look of each individual and the use made of it. The pedological approach to environmental education began in the 90s of XX century, seeking to awaken rational land use and conservation, both in formal and non-formal education. In Brazil, called, Soil in School Project started in 2003, with the same goal. The National Curriculum Parameters ( $P C N s$ ) bring the soil theme as a crosscutting theme in elementary school, both in the subjects of Science and Geography. We investigate what children of elementary school know about soil in São Paulo-SP. For this, we participated in workshops and offer lectures for children and teachers. We realized that the child know about soil like people in general, even having already learned about the subject in school. In this regard, we emphasize the importance of education in Soils for it to be seen not only for economic purposes, but also as an important element of the environment and the maintenance of life.
\end{abstract}

Keywords: Soil Education, Soil in School Project, Elementary Education.

* debolive@usp.br

Recebido: 17/03/2014 Aceito: 17/03/2014 


\section{Introdução}

$\mathrm{O}$ solo é visto como um elemento do meio ambiente, porém, seu conceito varia de acordo com o ponto de vista de quem o define. Para os profissionais do ramo da agricultura, o solo é visto como uma fonte de renda, pois o solo irá servir de suporte para as plantas. Para alguns profissionais da engenharia, o solo serve de substrato para a construção de estradas, prédios etc e para os profissionais da mineração, o solo dificulta que seja alcançada certa riqueza mineral que se encontra sob ele.

Para as crianças do Ensino Fundamental, o conceito de solo é muito abstrato, pois muitas vezes o estudante não tem contato algum com o solo no seu dia a dia, principalmente em uma cidade muito impermeabilizada como São Paulo.

Com anos de experiência lecionando em escolas públicas e privadas na grande São Paulo, pudemos perceber o que pensam as crianças sobre o solo, o que aprendem sobre o solo em sua escola e nos livros didáticos e paradidáticos.

\section{$2 \mathrm{O}$ olhar da criança sobre o solo}

Procuramos relatar algumas perguntas e as respostas mais comuns entre as crianças do Ensino Fundamental. Em conversas com as crianças pudemos verificar o que pensam sobre o solo:

1 - O que é solo?

É o chão.

2 - De onde nasce o solo?

Vem da terra.

3 - Quando o solo nasce?

Não sei.

4 - Qual o tamanho do solo?

Mais ou menos 1 metro.

5 - Quais são as cores do solo?

Marrom e preto.

6 - O que tem dentro do solo?

Tem os bichinhos e as pedras.

7 - O solo é importante?

Sim, porque sem ele a gente ia cair.

8 - O solo tem vida?

Tem, porque senão não teria as plantas.

9 - Você já encontrou animais no solo? Quais?

Minhoca, formiga e tatu bolinha.
10 - O solo fica doente?

Fica.

11 - Como sabemos que ele está doente?

Quando as plantas estão morrendo.

12 - Quando o solo está doente, o que devemos fazer para curá-lo?

Colocar mais adubo nele.

13 - O que você mais gostou de aprender sobre o solo?

Da experiência com sementes.

Estas respostas nos fizeram pensar sobre como elas observam e percebem o solo e que os conceitos básicos podem ser melhor trabalhados em atividades didáticas, que são enriquecedoras, na medida que despertam o interesse e a curiosidade científica.

\section{O tema solos e os parâmetros curricula- res nacionais}

A Educação Ambiental começou a ter uma preocupação em inserir o tema solo recentemente, na década de 1990 em alguns países europeus, na Rússia, na Austrália, na Índia e no Brasil (Abbot et al., 2002; Badrinath et al., 2002).

A iniciativa de divulgação do uso racional e sustentável do solo e de sua conservação fez que que se estabelecesse em 1998 uma comissão intitulada Soil Education and Public Awareness, na Sociedade Internacional de Ciência do Solo (IUSS, 2003).

Mais recentemente, após o ano 2000, o ensino de solos passou a fazer parte, mais efetivamente, de alguns projetos de Educação Ambiental no Brasil. Muggler (2006) em um artigo publicado na Revista Brasileira de Ciência do Solo, sugere que o termo Ensino de Solos seja substituído por Educação em Solos, na Sociedade Brasileira de Ciência do Solo, pelo fato de que os estudantes brasileiros precisam ter uma conscientização pedológica e não só receber passivamente o conceitos sobre o solo.

A Educação em Solos tem como objetivo conscientizar a importância do solo na vida das pessoas. Neste sentido, o solo deve ser visto como componente essencial do meio ambiente e da vida, assim deve ser conhecido e preservado da degradação. (MUGGLER et al, 2006)

Na estrutura da Sociedade Brasileira de Ciência do Solo (SBCS), a Educação em Solos faz parte da Divisão IV, denominada 'Solos, Ambiente e Sociedade', na Comissão 4.1 - Educação em Solos e Percepção Pública do Solo. Portanto, amparada pela instituição maior em solos no Brasil, a Educação em Solos tem também como um dos objetivos popularizar o conhecimento científico acerca do solo tanto na educação formal como na não formal. (MUGGLER et al, 2006). A missão dessa comissão é contribuir na construção do elo, atualmente inexistente ou 
muito tênue, entre a Ciência do Solo e a Sociedade, por meio do desenvolvimento, em cada cidadão, da consciência da importância do solo para a vida (IUSS, 2003).

Nos Parâmetros Curriculares Nacionais (PCNs), o solo é um tema tranversal, isto é, deve ser tratado em várias disciplinas curriculares, como por exemplo, no Ensino Fundamental, em Ciências e Geografia (BRASIL, 1997). Observando os livros didáticos de Geografia e Ciências do Ensino Fundamental e livros paradidáticos, conseguimos identificar os conteúdos sobre o solo e suas deficiências. Em geral, o conceito de solo aparece em segundo plano, mal elaborado e com conceitos incorretos ou ultrapassados. O solo é visto somente do ponto de vista econômico, não havendo nenhuma ou pouca relação com sua origem, formação, pontencialidades, nova classificação, problemas e conservação.

\section{$4 \mathrm{O}$ projeto solo na escola}

A ampliação da Educação em Solos e sua popularização trouxe iniciativas de projetos de cultura e extensão universitária em várias instituiçõoes no Brasil.

O Projeto Solo na Escola, pioneiro na criação do elo entre conhecimento científico e sociedade, teve início na Universidade Federal do Paraná, no Departamento de Solos e Engenharia Agrícola, com uma exposição didática sobre o tema solo, no ano de 2003. O objetivo do projeto é de promover, nos professores e estudantes do ensino fundamental e médio, a conscientização de que o solo é um componente do ambiente natural que deve ser adequadamente conhecido e preservado tendo em vista sua importância para a manutenção do ecossistema terrestre e sobrevivência dos organismos que dele dependem (LIMA, 2002). Alguns anos mais tarde, foi implantado o Projeto Solo na Escola, na Escola Superior de Agricultura Luiz de Queiroz da Universidade de São Paulo, em Piracicaba, que teve o apoio da equipe do Projeto Solo na Escola da UFPR. Com o mesmo objetivo e recebendo o apoio das equipes da UFPR, Esalq-USP e da Pró reitoria de Cultura e Extensão Universitária da USP, implantamos o Projeto Solo na Escola no Parque CienTec da USP.

Durante os anos de elaboração de nosso projeto, participamos de três Simpósios de Educação em Solos, duas Semanas de Ciência e Tecnologia no Parque CienTec, oferecemos diversos cursos para professores da rede pública do Estado de São Paulo e palestras em escolas para crianças do Ensino Fundamental.

O projeto conta com experimentos didáticos e lúdicos sobre o solo, onde os estudantes podem interagir e manusear o solo. Os temas tratados são: material de origem do solo, formação do solo, perfil de solo, cor do solo, textura e granulometria do solo, porosidade do solo, carga elétrica do solo, acidez e alcalinidade do solo, erosão do solo, compactação do solo, solo como filtro, magnetismo do solo, fauna do solo, dentre outros.

\section{Exemplos de experimentos com solos}

Quando apresentamos alguns experimentos às crianças, e mesmo aos professores, em cursos de formação, todos ficam muito entusiasmados com as inúmeras propriedades dos solos, muito além da experiência com sementes.

Todos ficam encantados ao ver que o solo tem cores muito além do marrom e do preto, e que podemos até pintar com tinta feita de solo.

Outra surpresa é quando utilizamos um imã e mostramos que alguns solos são atraídos por ele e outros não, devido a presença do ferro.

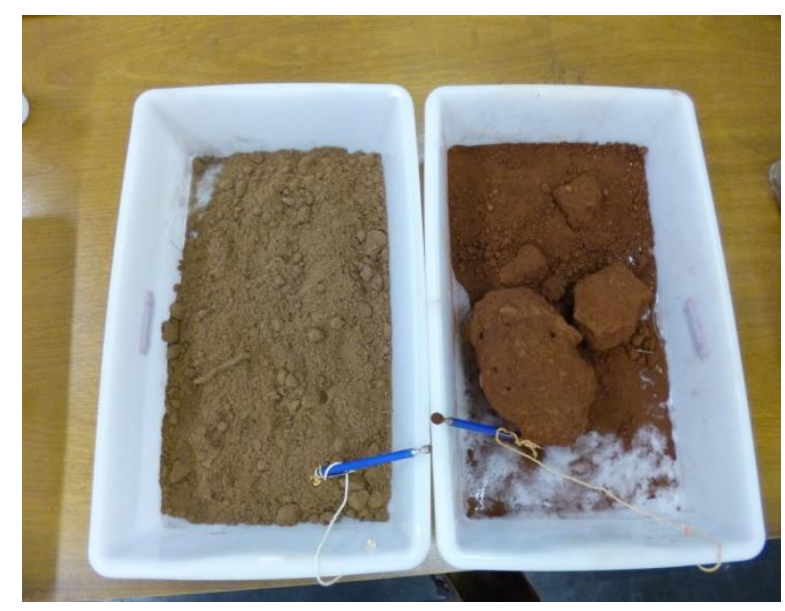

Figura 1:Magnetismo do solo. Solo da esquerda com pouco ferro e solo da direita com mais ferro.

Como pode o solo nascer de uma pedra? O conceito de intemperismo é desenvolvido em um experimento que mostra a rocha sã, depois a rocha já alterada, até a formação do solo e seus horizontes.

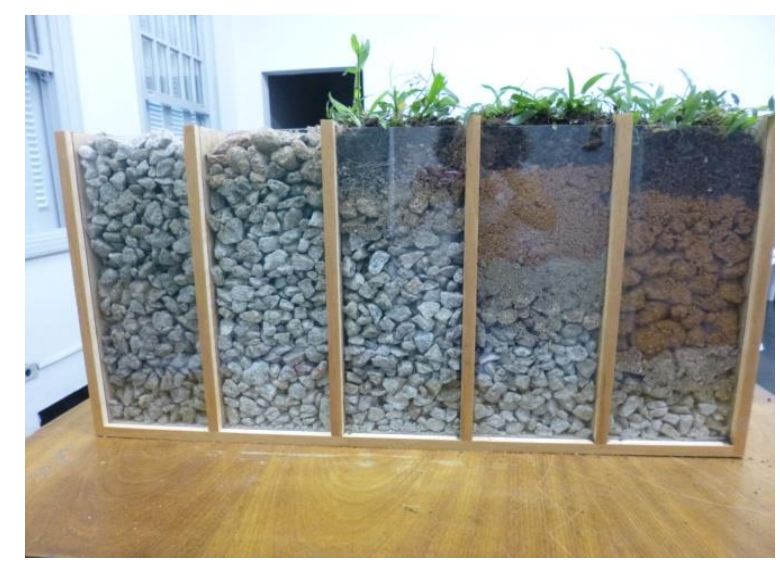

Figura 2: Formação do solo, da rocha sã até o perfil de solo. 
O solo tem camadas de cores diferentes? O estudante pode observar os horizontes de um solo.

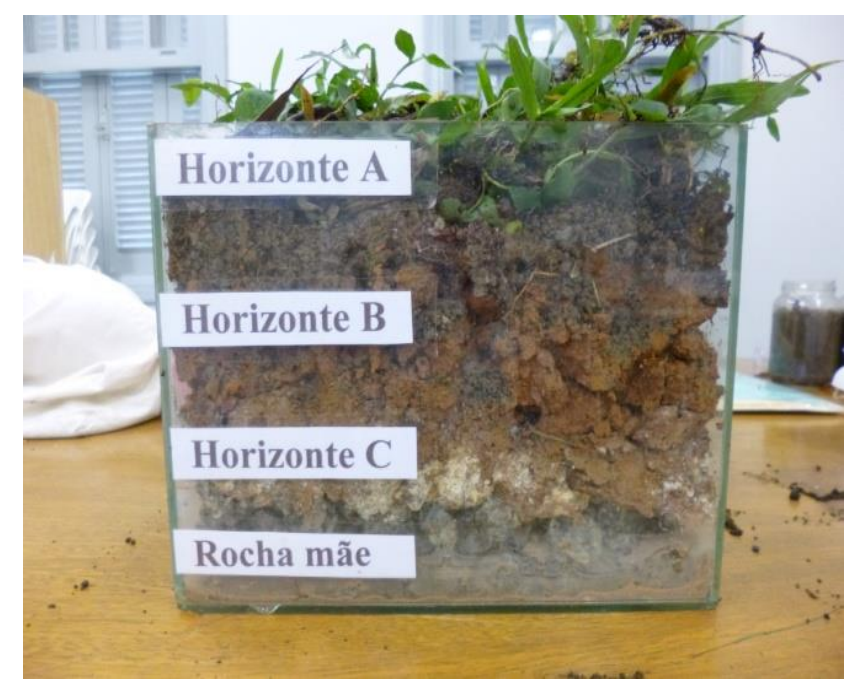

Figura 3: O perfil de solo.

Mas o que tem no solo além de pedra e bichinhos? A oportunidade de ver que o solo tem areia, silte e argila e poder observar os grãos de areia e silte sob uma lupa é uma atividade muito enriquecedora. Como pode ter areia igual a da praia dentro do solo? E essa argila, dá para fazer um vaso com ela?

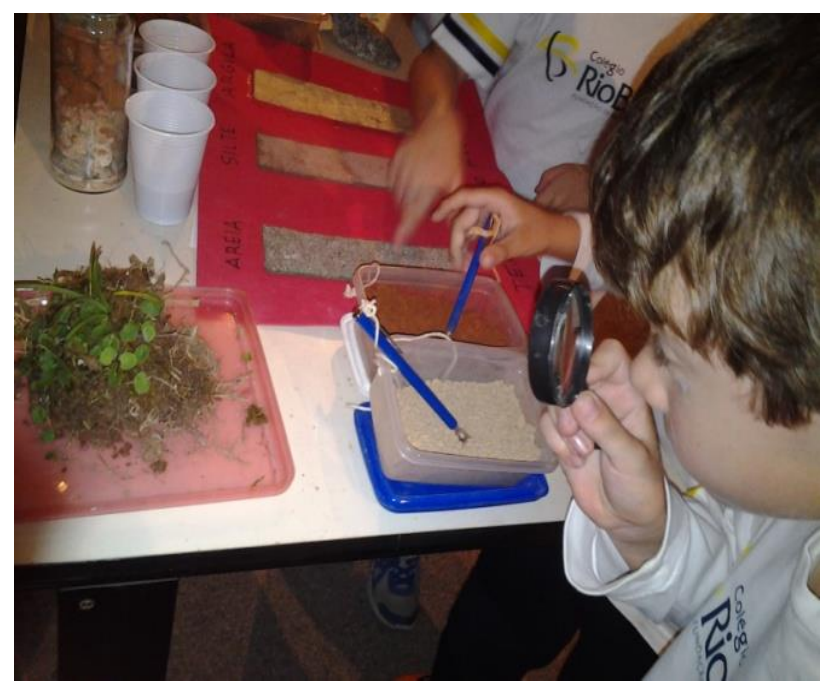

Figura 4: Observação de um torrão de solo e da textura do solo.

Demonstrar que alguns solos podem conduzir eletricidade e acender uma lâmpada através de sua matéria orgânica também é uma grande descoberta tanto para os estudantes como para seus professores.

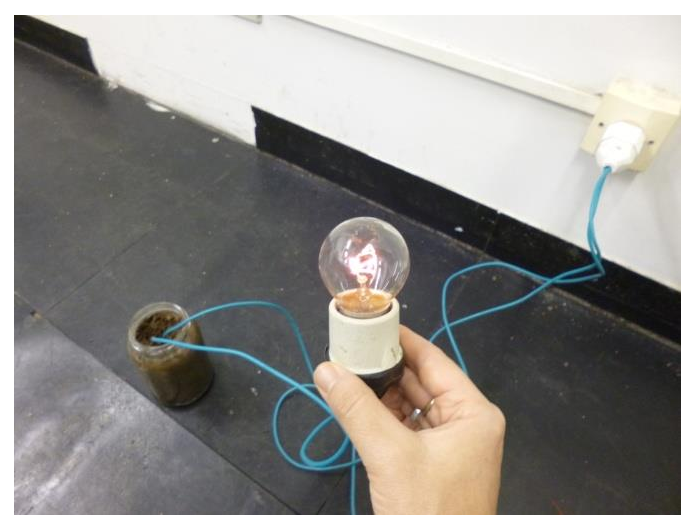

Figura 5: O solo como condutor de eletricidade

Se eu desmatar o solo e chover, ele pode ser carregado pela chuva?

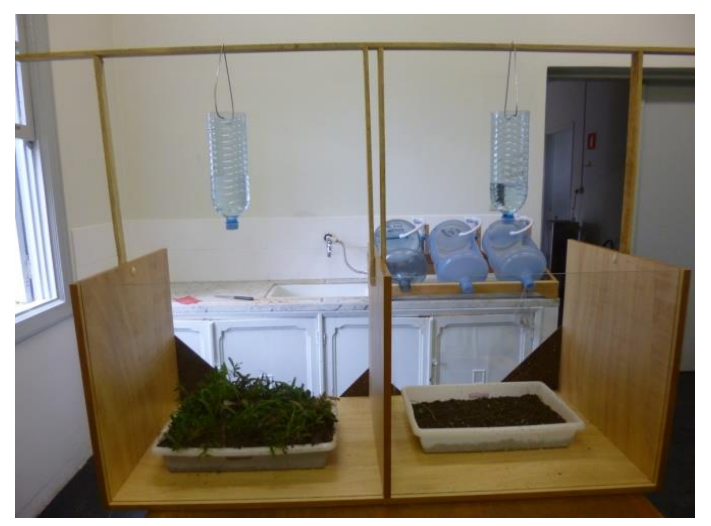

Figura 6: Experimento demonstrando que o impacto da gota da chuva é menor no solo com vegetação e maior no solo exposto (efeito splash).

O solo age como um filtro, por isso ele é facilmente contaminado quando resíduos poluentes são depositados nele.

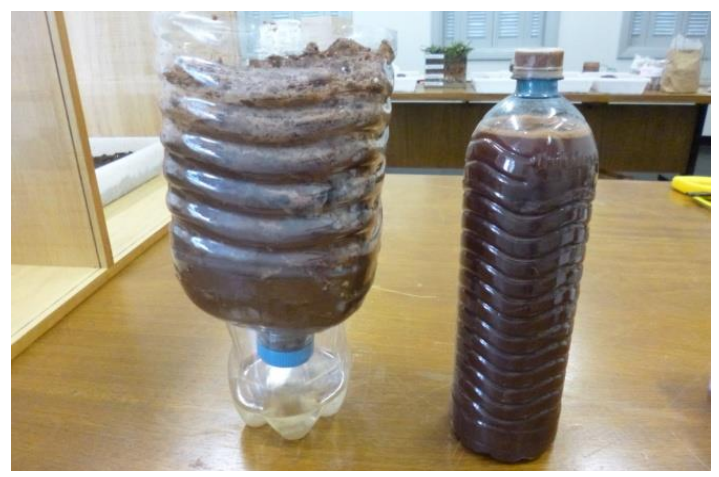

Figura 7: O solo como filtro. Observar que após a deposição da água barrenta, o solo filtra a água, que sai mais limpa. 
Com todas estas novas descobertas, a criança começa a perceber que o solo interage com todo o meio ambiente e que há muito a aprender sobre o solo.

\section{Considerações finais}

Devido à importância do solo na manutenção da vida, percebemos que as crianças mesmo tendo estudado o tema solo em sala de aula, têm a visão muito restrita do que é solo e de suas propriedades.

Os livros didáticos apresentam conceitos muito superficiais, ultrapassados e incorretos, pois a deficiência também está presente na formação dos professores e autores de livros didáticos sobre o tema solo.

O solo não é tão valorizado nos estudos de educação ambiental, assim como são o ar, a água, os seres vivos e as rochas.

Cabe à Educação em Solos o papel de propagar e popularizar o conhecimento do solo na sua totalidade, não só para fins econômicos, como observamos que tem sido divulgado tanto na educação formal como na não formal, para que se tenha um uso racional deste recurso natural tão importante para a manutenção da vida, que é pouco conhecido e deve ser preservado.

\section{Agradecimentos}

Agradecemos a toda a equipe do Grupo de Educação em Solos do Departamento de Geografia da USP (http:// educaemsolos-usp.blogspot.com.br/), à Pró-reitoria de Cultura e Extensão Universitária da USP, pelo apoio financeiro para a implantação do Projeto Solo na Escola do Parque CienTec-USP e aos Projetos Solo na Escola da UFPR e da Esalq-USP, pelo incentivo e apoio.

\section{Referências}

ABBOTT, L.; MILTON, N.; MURPHY, D. \& HAQ, K. Introducing the concept of soil biological fertility to land managers: A soil biology education program. In: WORLD CONGRESS OF SOIL SCIENCE, 17., Thailand, 2002. Abstracts. Bangkok, IUSS, 2002. p.1686.

BADRINATH, M.S.; CHIKKARAMAPPA, T. \& JAYAPRAKASH, S.M. Karnataka Soil Reference Information Centre (KASRIC): A novel center for soil science education in India. In: WORLD CONGRESS OF SOIL SCIENCE, 17., Thailand, 2002. Abstracts. Bangkok, IUSS, 2002. p.1687.

BRASIL. Ministério de Educação. Parâmetros Curriculares Nacionais - Apresentação dos temas transversais e ética. Brasília, Secretaria de Educação
Fundamental/ MEC, 1997. v. 8. 143p.

MUGGLER, C. C; SOBRINHO, F. de A. A. P.; MACHADO, V. A. Educação em solos: princípios, teoria e métodosRevista Brasileira de Ciência do Solo, vol. 30, núm. 4, agosto, 2006, pp. 733-740.

IUSS. Soil Education and Public Awareness Comission. Newsletter, 1:1-4, 2003.

LIMA, M.R. O solo no ensino fundamental: Situação e proposições. Curitiba, Universidade Federal do Paraná, 2002. 33p. 